\title{
Blended Learning Will Be Applicable in Maritime Education and Training
}

\author{
Yu Haiyan \\ Department of Navigation, Faculty of Merchant Marine College, Shanghai Maritime University, Shanghai, CHINA
}

\begin{abstract}
With the revision work of the IMO Model Course 6.09, the trainee-centered methodology is greatly highlighted, together with the newly merging technology for education, especially for language learning. This paper will consider blended learning, for instance. Blended learning is adorable for many educators in recent years, which demonstrates the principle of student-centered as well as alternates the role of the teachers from the traditional way. MOOC (Massive Online Open Course) is initiated in most schools as well, for the purpose of mutual share of the best education in the world. Within the framework of blended learning, the MOOC can also be the essential section in a whole circle. With some successful examples for the application of blended learning in elementary and middle schools, the author is suddenly inspired to make assumptions for better MET (maritime education and training): the blended learning is applicable in MET to stimulate the students' initiatives.
\end{abstract}

Key words: Blended learning, MOOC, MET.

\section{Introduction}

Different from the previous years, the salary for seafarers has greatly declined under the effect of currency devaluation and rising-up salary ashore. A great amount of young people reject to work onboard ship. However, the senior officers still possess a higher income as well as a higher social status. Firstly, the traditional means of the seafarers' certification training and examination is always confined to a fixed time each year, which can be overlapped with the trainees' sea voyage. More significantly, the seafarers' competency is a vital factor for their employment. In order to conform to the requirements of STCW 2010 manila amendments, the IMO Model Course 3.17 was revised according to the KUP (Knowledge, Understanding and Proficiency) by the STCW conventions. It is obvious that proficiency-based or competency-based study is the optimal objective for maritime English education and training. But the criteria of competency is inadequately and difficultly evaluated and assessed only in terms of the mid-term

Corresponding author: Yu Haiyan, Master, teaching assistant. research field: maritime English. examinations, final examinations, and regular assignments. With the assistance of blended learning, Sturgis [1] held the opinion that "students are empowered to progress at their own pace, becoming active, engaged, and more independent learners”.

\section{The Current Situation of Blended Learning at Schools and/or Universities}

MOOC (Massive Online Open Course) is quite popular and utilized in many top universities for the benefit of sharing accessible high-quality courses of variable subjects. However, these online courses can only be the supplemented materials for the students' better understanding of their learned or learning knowledge. For the realization of competence, there is still a gap, which cannot be narrowed or diminished only depending on MOOC. With the available world-class online systematic courses updating hour by hour, how to make full use of these optimal resources for better education is a question to be considered. The new innovative teaching and learning approach-blended learning is on the way to make a more successful education for the next generation. 
Bonks [2] defined that " $\mathrm{BL}$ (blended learning) is the combination of instruction from two historically separate models of teaching and learning: traditional face-to-face learning systems and distributed learning systems." It is prevalent for a decade in both K-12 education schools as well as higher education institutes. The traditional classroom education has been overturned. Traditionally, the teachers will deliver their lectures in front of their students with a planned teaching syllabus, some selective teaching aids like hard version textbooks, projectors, computers, etc., some selective classroom activities like Question \& Answers, group discussion, presentation, etc. The whole process of teaching seems having no weak link, but the outcomes are not satisfactory. No clear sign of progress has been made. Differently, the blended learning has an innovative perspective to organize a course. Reversely, under the light of blended learning, the students will complete their assignment in the classroom assisted by their teacher and learn the lessons after class. Within the framework of blended learning, the students will be involved in three rotations: individual online learning; teachers' lectures; and small group project. That means the students can learn the courses online at home, in the library or in the computer-aided room ahead of time with accessible wireless connection. With some questions and assigned project in hand, they come to the teachers.

For K-12 education, take the Public Summit School as an example, some learners will be equipped with a Pad to learn their online courses, some of them will have small group project-normally their assignment, and some of them will be selected to attend a mini course with the instructor explaining the learned knowledge. All the above mentioned procedure is conducted simultaneously and all the students will be immersed into these three rotations on each course. For higher education, take MIT for instance, the students can select their courses on will, and they do not have to attend their classes. They can learn the subject courses online and take the quizzes and exams online, if the result is satisfactory. They will pass the course with no attendance in classrooms. The whole process of learning can be monitored and tracked by their subject lecturers, the assessment means is also multiple except for the quiz and exams, some assigned project have to be completed within a small group face-to-face. If the students have any questions and confusions about the online learning and group project work, they can choose to attend the lecturers for consultation.

\section{The Convincing Benefits from Blended Learning}

Review from the above two models, the convincing benefits the educator can extract from blended learning can be summarized as below:

Students can access the online courses at any time, at any place, at any pace, which stimulates the students' initiatives to study instead of receiving the lectures passively under a seat-time based system.

The students' data is recorded into the information system, and the subject lecturers are able to assign them the project work according to their different background knowledge, which increases the chances for the students-to-students and students-to-teachers face-to-face interaction as well as their knowledge diversity.

The traditional education cannot meet all the students' need but teach them with unified criteria, which turns to be that the top students cannot be fed fully with deeper and complicated knowledge while the fall-behind students move ahead with more difficulty even want to quit. With the blended learning scheme, all the individual students can be assessed into individualized rank, and then all of them will acquire the competence with individualized tailored teaching syllabus.

With the data assessment including the students' learning results from the online courses, project performance, and others, the students' competence can be told quickly and continuously with effective way to replace the burdensome way to assign many teachers to 
spend one or two days to grade hundreds of exam papers.

\section{The Application of Blended Learning to MET}

When it comes to the MET (Maritime Education and Training) area, the blended learning will also blossom in this field. Take maritime English as an example, the IMO Model Course 6.09 can function as a guideline for instructors to plan, organize and deliver a course. As for the detailed teaching syllabus, the IMO Model Course 3.17 can be referred for the seafarers' training from all rank-engineers from engine departments, officers from deck department, and Electric Technician Officers.

Alike with other subjects, the preparation work is time-consuming and tiresome for the implementation of these three rotations of blended learning. Accordingly, the curricular also needs consideration including the tangible online courses, selective project themes, and others.

\subsection{Individual Online Learning Rotation}

The online courses of maritime English should be produced in compliance with the IMO Model Course 3.17 as well as each state member's national standards for seafarers' training. With the establishment of maritime English learning online platform, theses online courses can be imbedded into this platform together with various types of quiz, tests to evaluate their learning. Also the students' online learning process and results can be notified by the instructors.

\subsection{Teachers'Lectures Rotation}

The professors will deliver their lectures aligned with syllabus of the online courses. Also the most frequency occurrence of the mistakes and difficulty points can be easily nominated from the database of the online learning platforms. The more detailed and emphasized explanation will clear the students' mind and face-to-face mentoring inspires the students' motivation to learn more. The teacher functions more like a facilitator other than a lecture producer. As Liu Siyang [3] stated: "it is of great importance for teachers to stimulate students to participate in classroom activities with the model of 'question-inquiry' and give full play to their dominant position.”

\subsection{Small Group Project Rotation}

The learned knowledge will be valuable only when it is applicable into the learners' future study and job. After learning the courses online, the students will be assigned to complete their project starting from small group work: discussion, making plans, implementation of the project. According to the statement from $\mathrm{Au}$ Thien Wan [4]: "The course has a mix of students from various backgrounds, varying levels of work experience and maturity, and, possibly, different globally cultural backgrounds. Obviously, this contributes to student diversity, and consequently to their interests, expectations, and approaches to study.”

The above stated three rotations will be implemented circularly. Ideally, a big classroom equipped with computers in section one for individual online learning rotation, round tables in section two for small group project rotation, projectors, blackboard and other teaching aids in section three for teachers' lecture rotation. Each section will be manned with assistance as well. The placement of the students will be determined by the teachers with the feedbacks of the students' performance from the online platform.

All the work cannot be conducted by a single teacher. All the teaching staff can be utilized more economic-friendly. The staff specialized in making teaching plans, they will work together to conduct the teaching syllabus; the experienced professors will deliver their lectures with the assistance of the colleagues with skillful computer knowledge to record and make the online lectures. The experienced laboratory assistances and instructors will assist in conducting a students' information management system to process the data of students' learning 
outcomes, and also provide the feedback to the teachers.

In terms of the blended learning, the students' competence can be monitored and updated contingently, each student shares the equality of being educated with the acquisition of the specific competence. For the maritime English learners, immersed into these three rotations, their drawbacks will emerge at a quicker time and also be corrected afterwards. Meanwhile, the team work is also highlighted, as well.

\section{Discussions and Conclusion}

With some successful examples of the application of blended learning in schools and universities, the applicability of blended learning in MET should not be doubted either. The following advantages will be envisaged:

Firstly, one of the constituent sections of blended learning-individual online learning rotation will facilitate the seafarer learners studying the relevant high-quality courses at any time, at any pace anywhere with available wireless connections. And also, the continuous tracking and analytic system will record the learners' learning process and efficiency including their drawbacks and difficulties in specific subjects or tasks, which will assist the learners as well as the teachers emphasizing on improving their understanding and accomplishing the specific tasks for the realization of competency.

Secondly, another section of blended learning-teachers' lecturers rotation will fill up the gap where the learners still have confusion about the specific tasks after the completion or near-completion of the online courses. Attending to the teachers' lectures will help the learners review the learned online lessons as well as understand the difficult points since the teachers also attain a feedback indicating the difficult points and exercises the learners of majority have encountered.
Thirdly, the next section of blended learning-small group project rotation will make all the learned knowledge practical and related to the future jobs. To test the learners' capability of using the learned knowledge, this section will be an ideal way with other additional abilities to be acquired. With a selective topic the teachers have assigned, the small group with different backgrounds and personal skills will work together to make specific strategic plans for the completion of their project. In the process of conducting their project, their roles will be allotted naturally. In general, the concept of team work has been highlighted which is helpful in their future jobs without any doubt.

Although the benefits of blended learning are evident, the obstacles are also of clear ground: the fund of establishing a computer-based classroom with installation of a well-designed software and assessment system, the technical instructors to analyze the learners' data continuously, etc.

Hopefully, with the continuously revised and updated conventions and IMO Model Courses and all the experienced shipping industry educators and experts worldwide, all the obstacle will be removed and MET will move in a newer and more successful direction within a blended learning framework.

\section{References}

[1] Sturgis, C., and Patrick, S. 2010. "When Success Is the Only Option: Designing Competency-based Pathways for Next Generation Learning." Nellie Mae Education Foundation.

[2] Bonks, C. J., and Graham, C. R. 2005. The Handbook of Blended Learning: Global Perspectives, Local Design. Pfreiffer Publishing.

[3] Liu, S. 2013. "Wed 2.0-Based Blended Learning in College English Teaching.” Proceedings of International Conference on Information, Business and Education Technology. Atlantis Press: 156-9.

[4] Wan, A. T. 2015. "How Can Learners Learn from Experience? A Case Study in Blended Learning at Higher Education.” International Journal of Information and Education Technology 5 (8): 615-9. 